\title{
A CASE-CROSSOVER STUDY OF SLEEP, FATIGUE, AND OTHER TRANSIENT EXPOSURES AT WORKPLACE AND THE RISK OF NON-FATAL OCCUPATIONAL INJURIES AMONG THE EMPLOYEES OF AN ITALIAN ACADEMIC HOSPITAL
}

FRANCESCA VALENT ${ }^{1,2,3}$, MARIKA MARIUZ ${ }^{2}$, GIULIA LIVA ${ }^{2}$, FABRIZIO BELLOMO ${ }^{4}$, DANIELA DE CORTI $^{4}$,
STEFANIA DEGAN ${ }^{4}$, ALBERTO FERRAZZANO ${ }^{4}$, and SILVIO BRUSAFERRO ${ }^{3,4}$

${ }^{1}$ Regional Health Directorate, Friuli Venezia Giulia Region, Udine, Italy

Epidemiologic Service

${ }^{2}$ University Hospital of Udine, Udine, Italy

Unit of Hygiene and Clinical Epidemiology

${ }^{3}$ University of Udine, Udine, Italy

Department of Medical and Biological Sciences

${ }^{4}$ University Hospital of Udine, Udine, Italy

Accreditation, Clinical Risk Management and Performance Assessment Unit

\begin{abstract}
Objectives: Transient exposure with acute effect has been shown to affect the risk of occupational injuries in various industrial settings and at the healthcare workplace. The objective of this study has been to identify transient exposures related to occupational injury risk in an Italian teaching hospital. Material and Methods: A case-crossover study was conducted among the employees of the University Hospital of Udine who reported an occupational injury, commuting accident, or incident involving biological risk in a 15-month period in the years 2013 and 2014. The matched-pair interval approach was used to assess the role of acute sleep deprivation whereas the usual frequency approach was used for other 13 transient exposures. Results: Sleep hours were not associated with the risk of injuries whereas a significant risk increase was associated with fatigue, rush, distraction, emergency situations, teaching to or being taught by someone, non-compliant patients, bloody operative/work field, excess noise, complex procedures, and anger. Conclusions: We identified transient exposures that increased the risk of occupational injuries in an Italian teaching hospital, providing indications for interventions to increase workers' safety at the healthcare workplace. Int J Occup Med Environ Health 2016;29(6):1001-1009
\end{abstract}

Key words:

Fatigue, Sleep duration, Case-crossover, Occupational injuries, Academic hospital, Italy

Funding: this research was co-funded by the Italian Ministry of Health through the "Ricerca Finalizzata Bando Giovani Ricercatori 2009," project code GR-20091569913. Project manager: Francesca Valent, M.D., M.Sc./M.P.H., Ph.D.

Received: May 27, 2015. Accepted: January 4, 2016.

Corresponding author: F. Valent, Regional Health Directorate, Friuli Venezia Giulia Region, Epidemiologic Service, Via Pozzuolo 330, 33100 Udine, Italy (e-mail: francesca.valent@regione.fvg.it). 


\section{INTRODUCTION}

Poor sleep and fatigue have repeatedly been associated with an increased risk of adverse safety outcomes [1,2], even among the healthcare workers. For instance, Patterson et al. [3] found that, among workers of the Emergency Medical Services, injuries occurred approximately 2 times more frequently in the case of poor sleep and 3 times more frequently in the case of fatigue than otherwise.

Other transient exposures at the workplace have been associated with the risk of injury. For example, various studies have shown that the risk of occupational traumatic hand injuries was significantly affected by transient factors at the workplace: a machine, tool, or work material that performed differently than usual; wearing gloves; performing an unusual task; doing a task using an unusual work method; being distracted or rushed; and feeling ill [4-6]. The effect of analogous factors has been studied in relation to the occurrence of occupational eye injuries [7].

When investigating the effect of transient exposures on the risk of occupational injuries, several researchers used the case-crossover design. In the case-crossover design [8,9] each subject acts as his/her own control. Thus, self-matching allows to control for the potential confounding effect due to factors which vary among individuals but are fixed within the same individual over relatively short periods of time: age, gender, risk propensity, visual acuity, reflexes, job experience, etc.

This design is well-suited for studying the effect of transient exposures with acute non-permanent effect: if a subject moves from exposed to unexposed states, the exposure immediately before an event, e.g., an injury, may be compared with the exposures of the same person at different times, when no event has occurred. Thus, exposures that act as triggers of the event may be identified.

Fisman et al. [10] used a case-crossover study to investigate the risk of sharp-related injuries in relation to several transient exposures among healthcare workers, finding that distraction, anger, and rushing were associated with the largest increases in risk.

In the University Hospital of Udine, a tertiary referral center in the North-East of Italy, employing approximately 3800 workers, about 450 occupational injuries, including commuting accidents and incidents involving biologic hazard, are recorded annually. Recently, different components of work-related stress have been detected in the hospital wards [11]; in addition, situations of personnel shortage and consequent exhausting work schedules in some wards have been reported in the local media as a potential cause of errors [12].

We decided to conduct a case-crossover study to identify transient factors that might affect the risk of occupational injuries among the employees of the University Hospital of Udine.

\section{MATERIAL AND METHODS}

Eligible study subjects for this case-crossover study were employees of the University Hospital of Udine who reported non-fatal injuries, including commuting accidents and incidents involving biological hazard, to the Clinical Risk Office of the Hospital, from 25 March 2013 to 3 July 2014, and who provided written informed consents to participate in the research. Before the start of enrollment, all the Hospital employees had been explained the purpose and background of the study through an information letter that had been included in their pay slips of February 2013. Workers reporting an injury were asked to provide their telephone numbers and were contacted within the shortest possible time by a single trained interviewer for a telephonic interview. The mean (M) and median $(\mathrm{Me})$ time that elapsed from injury occurrence to the interview were 4.4 days and 4 days, respectively (standard deviation $(\mathrm{SD})=4.1$ )

The interview was conducted using a semi-structured questionnaire collecting information on socio-demographic characteristics of the worker, job characteristics 
(the occupation, department type, shifts, exposure to hazards, etc.), injury characteristics (a type of injury, task performed at the time of injury, day and time of occurrence), sleep quality and quantity on the day of the injury and on the prior working day.

Workers who suffered injuries other than commuting accidents were also asked to report their exposure to fatigue, rush, distraction, working in an emergency situation, teaching to someone, being taught by someone, personnel shortage, non-compliant patients, blood in operative field or work field, excess noise, complex procedure, music, and anger at the time of the injury and to estimate the usual frequency of those exposures on the previous working month, expressed as the percent of their working time they perceived to be exposed. To collect data on the usual frequency of exposure, we adopted questions in the format used by Fisman et al. [10].

Our questionnaire also included sections regarding lifestyle, medical problems, chronic sleep disturbances, the Epworth Sleepiness Scale, and the Horne-Östberg morningness-eveningness questionnaire (MEQ). Out of these additional sections, the MEQ was only used for the purpose of the case-crossover study. The MEQ scores were categorized into 3 chronotypes: "morning type" (score 59-86 points), "neither morning nor evening type" (42-58 points), "evening type" (16-41 points). The duration of the complete interview was approximately $30 \mathrm{~min}$ on average.

\section{Statistics}

The effect of sleep duration on the risk of injury was evaluated according to the case-crossover matched-pair interval approach. For each injured subject, the day immediately before the injury represented the case window for the analysis whereas the previous working day was the control window. The statistical significance of the difference in sleep duration reported by each worker between the 2 windows was assessed through the t-test for paired data. A p-value $<0.05$ was considered statistically significant.

The effect of sleep duration on the risk of injury was assessed through a conditional logistic regression model, which was adjusted for the potential confounding effect of the day of the week (both sleep duration and the opportunity to be injured may be different on different days of the week). The relative risk (RR) was reported as the measure of association. The precision of the estimate was expressed through the $95 \%$ confidence interval (CI). The agreement between the sleep amount in the case and control windows was reported according to the question "Compared to the previous working day, on the day of the injury did you sleep fewer hours, more hours, or the same number of hours?" and the sleep amount resulting from the difference in the reported actual number of sleep hours in the 2 days was assessed through the kappa statistics and was used as a measure of validity of self-reports.

The effect of the other 13 transient exposures (fatigue, rush, distraction, emergency situation, teaching to someone, being taught by someone, personnel shortage, noncompliant patient, blood in operative or work field, excess noise, complex procedure, music, and anger) on the risk of injury was assessed according to the case-crossover usual frequency approach. The RR and 95\% CI were estimated using the Mantel-Haenszel estimator for person-time data, as exemplified in previous studies [4-6,10], the individual being the stratifying variable. Relative risks were based on the ratio of the observed frequency of exposure to each factor at the time of the injury (hazard period) to the reported frequency of exposure in the past workmonth (control period). Workers who were never exposed to a certain factor were automatically excluded from the analyses regarding such a factor.

To assess whether the effect of the transient exposures on the risk of injury was modified by job and injury characteristics and by chronotype, we attempted additional analyses stratified by a worker's occupation, night shifts, 
injury type, and worker's chronotype. Because of the limited sample size in most strata, only some models could be run. The results of those analyses restricted to certain subgroups were presented as sensitivity analyses.

All the analyses were performed using SAS version 9.2 (SAS Institute Inc., Cary, NC, USA).

\section{Ethics}

Approval from the Ethics Committee of Udine, Italy, was obtained on 6 November 2012. An informed consent form was signed by all the study participants.

\section{RESULTS}

Two hundred employees of the University Hospital of Udine suffered occupational injuries and agreed to participate in the research during the 15 months of the study
(47\% of the 425 injuries reported in the same period). The characteristics of the injured subjects and of the injuries are illustrated in the Table 1.

Compared to the previous working day, most subjects $(\mathrm{N}=155,77.5 \%)$ reported "the same sleep quality" on the day of the injury, 4 (2\%) reported having slept better and $41(20.5 \%)$ having slept worse on the day of injury; 158 (79.9\%) reported "the same hours of sleep" in both days, $3(1.5 \%)$ reported more hours whereas $39(19.5 \%)$ reported fewer hours on the day of injury. Comparing the reported actual sleep duration on the 2 days, 35 subjects $(17.5 \%)$ reported shorter sleep duration on the day of the injury than on the previous working day whereas 28 (14\%) reported longer duration. The agreement between sleep difference estimated with the 2 different methods is shown in the Table 2. The sleep

Table 1. Characteristics of workers of the University Hospital of Udine, Italy, injured from 25 March 2013 to 3 July 2014

\begin{tabular}{|c|c|c|}
\hline \multirow[t]{2}{*}{ Characteristics } & \multicolumn{2}{|c|}{$\begin{array}{l}\text { Respondents } \\
(\mathrm{N}=200)\end{array}$} \\
\hline & $\mathrm{n}$ & $\%$ \\
\hline \multicolumn{3}{|l|}{ Sex } \\
\hline male & 37 & 18.5 \\
\hline female & 163 & 81.5 \\
\hline \multicolumn{3}{|l|}{ Age } \\
\hline 20-29 years & 33 & 16.5 \\
\hline $30-39$ years & 52 & 26.0 \\
\hline $40-49$ years & 74 & 37.0 \\
\hline $50-59$ years & 35 & 17.5 \\
\hline$\geq 60$ years & 6 & 3.0 \\
\hline \multicolumn{3}{|l|}{ Job } \\
\hline physician & 47 & 23.5 \\
\hline non-physician health professional & 89 & 44.5 \\
\hline administrative & 7 & 3.5 \\
\hline other & 57 & 28.5 \\
\hline \multicolumn{3}{|l|}{ Chronotype } \\
\hline morning type & 83 & 41.5 \\
\hline neither type & 99 & 49.5 \\
\hline evening type & 18 & 9.0 \\
\hline
\end{tabular}


Table 1. Characteristics of workers of the University Hospital of Udine, Italy, injured from 25 March 2013 to 3 July 2014 - cont.

\begin{tabular}{|c|c|c|}
\hline \multirow[t]{2}{*}{ Characteristics } & \multicolumn{2}{|c|}{$\begin{array}{l}\text { Respondents } \\
(\mathrm{N}=200)\end{array}$} \\
\hline & $\mathrm{n}$ & $\%$ \\
\hline \multicolumn{3}{|l|}{ Department type } \\
\hline medical & 94 & 47.0 \\
\hline surgical & 72 & 36.0 \\
\hline laboratory & 19 & 9.5 \\
\hline administrative & 8 & 4.0 \\
\hline other & 7 & 3.5 \\
\hline \multicolumn{3}{|l|}{ Working schedule } \\
\hline shifts, with nights & 90 & 45.0 \\
\hline shifts, no nights & 48 & 24.0 \\
\hline no shifts & 35 & 17.5 \\
\hline variable & 27 & 13.5 \\
\hline \multicolumn{3}{|l|}{ Exposure } \\
\hline lifting weights & 129 & 64.5 \\
\hline handling chemicals & 156 & 78.0 \\
\hline potentially infected biologic materials & 185 & 92.5 \\
\hline \multicolumn{3}{|l|}{ Type of injury } \\
\hline trauma & 62 & 31.0 \\
\hline incident involving biological hazard & 97 & 48.5 \\
\hline incident involving chemical hazard & 3 & 1.5 \\
\hline commuting accident & 38 & 19.0 \\
\hline \multicolumn{3}{|l|}{ Injury occurrence } \\
\hline \multicolumn{3}{|l|}{ time } \\
\hline morning (6:00 a.m. - 1:59 p.m.) & 121 & 60.5 \\
\hline afternoon (2:00 p.m. - 9:59 p.m.) & 68 & 34.5 \\
\hline night (10:00 p.m. - 5:59 a.m.) & 11 & 5.5 \\
\hline \multicolumn{3}{|l|}{ working hour } \\
\hline 1st & 15 & 7.5 \\
\hline 2nd-5th & 137 & 68.5 \\
\hline$\geq 6$ th & 48 & 24.0 \\
\hline \multicolumn{3}{|l|}{ day of the week } \\
\hline Sunday & 11 & 5.5 \\
\hline Monday & 34 & 17.0 \\
\hline Tuesday & 33 & 16.5 \\
\hline Wednesday & 30 & 15.0 \\
\hline Thursday & 39 & 19.5 \\
\hline Friday & 41 & 20.5 \\
\hline Saturday & 12 & 6.0 \\
\hline
\end{tabular}


Table 2. Agreement between 2 self-reports of sleep amount on the day of occupational injury and on the previous working day among employees of the University Hospital of Udine, Italy ${ }^{\mathrm{a}}$

\begin{tabular}{|c|c|c|c|c|}
\hline \multirow[t]{2}{*}{$\begin{array}{c}\text { Sleep amount } \\
\text { (self-report No. 1) }\end{array}$} & \multicolumn{4}{|c|}{$\begin{array}{c}\text { Answers to the question } \\
\text { "Compared to the previous working day, } \\
\text { on the day of the injury did you sleep fewer hours, } \\
\text { more hours, or the same number of hours?" } \\
\text { (self-report No. 2) } \\
{[\mathrm{n}(\%)]}\end{array}$} \\
\hline & $\begin{array}{c}\text { fewer hours of sleep } \\
\text { on day of injury }\end{array}$ & $\begin{array}{c}\text { same hours of sleep } \\
\text { on both days }\end{array}$ & $\begin{array}{l}\text { more sleep hours } \\
\text { on day of injury }\end{array}$ & total \\
\hline Fewer hours of sleep on day of injury & $20(10.0)$ & $16(8.0)$ & $0(0)$ & $36(18.0)$ \\
\hline Same hours of sleep on both days ${ }^{\mathrm{b}}$ & $15(7.5)$ & $122(61.0)$ & $0(0)$ & $137(68.5)$ \\
\hline More sleep hours on day of injury & $4(2.0)$ & $20(10.0)$ & $3(1.5)$ & $27(13.5)$ \\
\hline Total & $39(19.5)$ & $158(79.0)$ & $3(1.5)$ & $200(100.0)$ \\
\hline
\end{tabular}

${ }^{\text {a }}$ Kappa statistics $=0.35$ (95\% confidence interval: 0.22-0.47).

${ }^{\mathrm{b}}$ The day of injury and the previous working day.

duration reported on the day of the injury was $6.35 \mathrm{~h}$ $(\mathrm{SD}=1.23, \mathrm{Me}=6$, range: $3-10)$; on the previous day it was $6.42 \mathrm{~h}(\mathrm{SD}=1.23, \mathrm{Me}=7$, range: $2-10)$ on average. The intra-worker difference in sleep duration between the day of the injury and the previous one was minimal $(0.06 \mathrm{~h}$ on average; $\mathrm{SD}=1.06)$ and non statistically significant (p-value of paired t-test 0.422 ). The RR of injury associated with each additional hour of sleep, adjusted for the day of the week, was 1.25 (95\% CI: 0.92-1.69). The results did not change after stratification by subject's chronotype.

The Figure 1 shows the frequency of transient exposures in the working month before the injury and the percentage rate of workers exposed at the time of the injury.

The corresponding RRs are illustrated in the Table 3. When we stratified the analyses by the role of the injured worker, the effect of several factors was much stronger among some professionals than in the overall pool of study subjects: in the analysis restricted to physicians, the RR associated with rush was 9.87 (95\% CI: 6.46-15.98), distraction-27.56 (95\% CI: 15.15-47.05), emergency situations8.59 (95\% CI: 4.76-15.49), non-compliant patients - 13.98 (95\% CI: 7.28-26.85), blood - 13.11 (95\% CI: 6.45-26.64), noise - 37 (95\% CI: 8.7-157.3). On the other hand, complex procedures did not appear to significantly increase the risk of injury ( $\mathrm{RR}=1.45,95 \% \mathrm{CI}: 0.69-3.05)$.

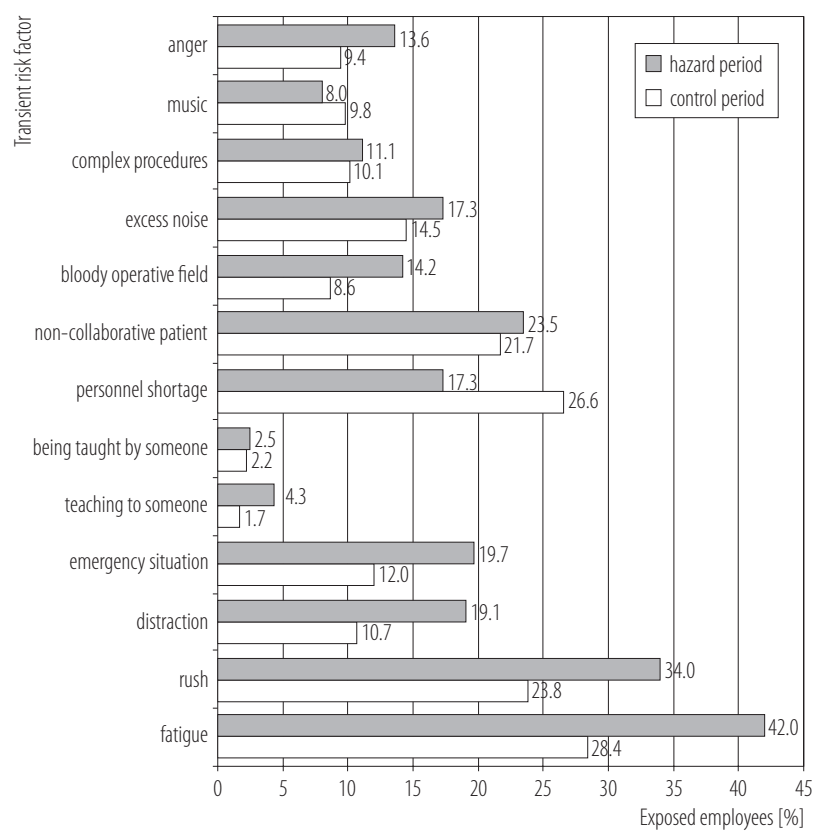

Fig. 1. Employees exposed to the transient risk factor at the time of injury (hazard period) and total person-time at work exposed to the same risk factors in the work-month before the injury (control period) in the University Hospital of Udine, Italy 
Table 3. Transient exposures and relative risks of occupational injuries among the employees of the University Hospital of Udine, Italy (usual frequency analysis)

\begin{tabular}{lcc}
\hline \multicolumn{1}{c}{ Transient risk factor } & RR & $95 \%$ CI \\
\hline Fatigue & 6.18 & $4.94-7.74$ \\
Rush & 4.66 & $3.75-5.80$ \\
Distraction & 5.10 & $4.06-6.40$ \\
Emergency situation & 4.60 & $3.45-6.13$ \\
Teaching to someone & 46.13 & $17.91-118.82$ \\
Being taught by someone & 10.00 & $2.02-49.57$ \\
Personnel shortage & 0.99 & $0.77-1.127$ \\
Non-compliant patient & 2.75 & $2.14-3.52$ \\
Bloody operative field & 5.05 & $3.64-7.00$ \\
Excess noise & 11.23 & $6.68-18.86$ \\
Complex procedures & 5.73 & $3.49-9.40$ \\
Music & 1.38 & $0.84-2.24$ \\
Anger & 2.34 & $1.77-3.08$ \\
\hline
\end{tabular}

${ }^{a}$ Commuting accidents not included in the analysis.

$\mathrm{RR}$ - relative risk; CI - confidence interval.

Among other health professionals, being taught by someone entailed a particularly high risk of injury ( $\mathrm{RR}=17.5,95 \%$ CI: 2.87-106.8), as complex procedures $\operatorname{did}(\mathrm{RR}=31.93,95 \% \mathrm{CI}:$ 8.99-113.33).

Among employees who worked on shifts including nights, the RR associated with fatigue was higher than among the overall pool of workers ( $\mathrm{RR}=8.74,95 \%$ CI: 6.32-12.1).

In analyses restricted to incidents involving biological risk, rush had a particularly strong effect (RR $=8.77,95 \%$ CI: 6.03-12.74).

Analyses restricted to morning-type workers showed that they were less vulnerable to fatigue than the overall pool of study subjects ( $\mathrm{RR}=3.78,95 \% \mathrm{CI}: 2.7-5.28)$ but more vulnerable to rush $(\mathrm{RR}=11.67,95 \% \mathrm{CI}: 7.73-19.54)$ and anger $(\mathrm{RR}=4.58,95 \% \mathrm{CI}: 2.65-7.92)$. Evening-type workers had a particularly high risk of injury associated with anger $(\mathrm{RR}=6.11,95 \% \mathrm{CI}: 2.07-11.03)$.

\section{DISCUSSION}

This is the first study of the association of transient factors and occupational injuries in an Italian hospital context. Through the case-crossover design, we could identify a number of risk factors. Most of the exposures that we investigated (i.e., fatigue, rush, distraction, emergency situations, teaching or being taught, non-compliant patients, blood on operative field, excess noise, complex procedures, and anger) turned out to be risk factors for occupational injuries in our study. Some of them (e.g., rush, distraction, anger) were consistently reported as risk factors for occupational injuries in previous literature [4-6,10]; others (e.g., fatigue, non-compliant patients, presence of blood, complex procedures, and teaching) increased the risk of injury in our hospital but not among healthcare workers elsewhere [10].

In a large hospital such as the University Hospital of Udine, with approximately 4000 employees, 1000 beds, over 30000 inpatients and 2 million outpatients, many of those exposures are likely to be common. Workers must be instructed to maintain concentration despite the chaotic work conditions that may characterize some healthcare environments $[13,14]$, trained to cope with anger, to handle conflicts, and to sooth interpersonal relationships, both with colleagues and with patients, and educated to limit noise as much as possible.

The finding that the effect of some transient exposures had different magnitude between physicians and other health professionals suggests that workers training should be tailored for each job type. We should also be aware that chronotypes might influence the susceptibility of a worker to the effect of transient stressing exposures and that coping with those factors might be particularly challenging for some individuals.

Rush, the effect of which is particularly strong in the case of incidents involving biologic hazard, is difficult to eliminate in a hospital since timely interventions on patients are often crucial for ensuring favorable outcomes. Although 
rush may also be a consequence of personnel shortage, in our study being short-staffed it was not associated with increased injury risk. Nonetheless, organizational changes should be conceived to improve work pace.

Our hospital has a teaching mission, and offers training and education to medical and nursing students and to physician residents, with part of the employees acting as supervisors and involved in regular teaching activities. Despite the very imprecise estimate, due to the very small number of injured workers involved in teaching activities either before the injury or in the previous month, teaching to someone or being taught by someone entailed an increased risk of injury (i.e., teaching activities were more frequent just before the injury than in the previous month). We should therefore analyze the way students and residents spend time in the hospital and possibly rethink the organization of the presence of students in the hospital wards, keeping in mind that the underlying reasons for the association between teaching activities and injuries may be different for students or residents and for professors or tutors.

Fatigue was an important risk factor for occupational injuries in our study, as in other healthcare settings [3]. Employees working on shifts experienced a particularly strong effect of fatigue, confirming that the design of good work schedules, the implementation of employer's strategies to reduce fatigue, and periodic assessments of sleep and fatigue among these workers may be useful [15].

Despite the effect of fatigue, we could not show an effect of acute sleep deprivation on the risk of injury. In fact, although more cases reported lower quality and shorter duration of sleep on the day of injury than on the previous working day, no significant differences appeared when the reported actual sleep duration was analyzed and no significant effect of sleep duration resulted from the matched-pair analysis. It is possible that acute sleep deprivation has little effect on the risk of injury, if we had hypothesized it in a previous research on sleep and road traffic accidents [16]. However, it is also possible that recall bias affected our results and prevented us to detect any association [8].

To assess the likelihood of recall bias, we included in the questionnaire a redundant question on sleep duration on the day of injury and on the previous working day, with different phrasing, as suggested by Maclure and Mittleman [9]. The agreement was only fair (kappa $=0.35)$, indicating that recall bias may exist to some extent. However, since we had no reliable external information to be used as the gold standard, we cannot describe the direction of the possible bias.

As with all retrospective studies using self-reports to quantify exposure, recall bias could also be present in our usual frequency analysis. We tried to minimize recall bias using a structured questionnaire and a well-trained unique interviewer. In addition, unlike case-control and cohort studies, in case-crossover studies the same subject reports exposures both in the hazard period and in the control period, making reporting more consistent. The RR estimates, however, could be overestimated (i.e., away from the null) if cases tended to underestimate the average exposure to transient factors in the past working month, while having a more vivid recall of the exposures at the time of the injury. The associations that we detected, however, are quite strong and most of them are consistent with other studies [4-6,10]. Therefore, should some degree of recall bias exist, it is unlikely that it explains the entire magnitude of the associations.

Approximately half of the employees who reported an injury during the study period participated in the research. Case selection bias could have been possible, if some of the transient factors of interest had influenced participation in the study. However, none of the transient factors that we investigated had legal implications or represented a disciplinary offence; therefore, we consider differential participation according to exposure status unlikely. 


\section{CONCLUSIONS}

In conclusion, this is the first Italian case-crossover study that has identified a number of transient risk factors for occupational injuries in a teaching hospital. Findings from this study provide useful information for interventions to increase workers' safety at the healthcare workplace.

\section{REFERENCES}

1. Lombardi DA, Folkard S, Willetts JL, Smith GS. Daily sleep, weekly working hours, and risk of work-related injury: US National Health Interview Survey (2004-2008). Chronobiol Int. 2010;27(5):1013-30, http://dx.doi.org/10.3109/07420528.2010. 489466.

2. Nakata A. Effects of long work hours and poor sleep characteristics on workplace injury among full-time male employees of small- and medium-scale businesses. J Sleep Res. 2011;20(4): 576-84, http://dx.doi.org/10.1111/j.1365-2869.2011.00910.x.

3. Patterson PD, Weaver MD, Frank RC, Warner CW, MartinGill C, Guyette FX, et al. Association between poor sleep, fatigue, and safety outcomes in emergency medical services providers. Prehosp Emerg Care. 2012;16(1):86-97, http:// dx.doi.org/10.3109/10903127.2011.616261.

4. Sorock GS, Lombardi DA, Hauser R, Eisen EA, Herrick RF, Mittleman MA. A case-crossover study of transient risk factors for occupational acute hand injury. Occup Environ Med. 2004;61(4):305-11, http://dx.doi.org/10.1136/oem.2002.004028.

5. Chow CY, Lee H, Lau J, Yu IT. Transient risk factors for acute traumatic hand injuries: A case-crossover study in Hong Kong. Occup Environ Med. 2007;64(1):47-52, http://dx.doi. org/10.1136/oem.2006.028589.

6. Choi WJ, Cho SI, Han SH. A case-crossover study of transient risk factors for occupational traumatic hand injuries in Incheon, Korea. J Occup Health. 2012;54(1):64-73, http:// dx.doi.org/10.1539/joh.11-0101-FS.

7. Blackburn J, Levitan EB, MacLennan PA, Owsley C, McGwin G Jr. A case-crossover study of risk factors for occupational eye injuries. J Occup Environ Med. 2012;54(1): 42-7, http://dx.doi.org/10.1097/JOM.0b013e3182398e1a.

8. Maclure M. The case-crossover design: A method for studying transient effects of the risk of acute events. Am J Epidemiol. 1991;133(2):144-53.

9. Maclure M, Mittleman MA. Should we use a case-crossover design? Annu Rev Public Health. 2000;21:193-221, http:// dx.doi.org/10.1146/annurev.publhealth.21.1.193.

10. Fisman DN, Harris AD, Sorock GS, Mittleman MA. Sharps-related injuries in health care workers: A case-crossover study. Am J Med. 2003;114(8):688-94, http://dx.doi. org/10.1016/S0002-9343(03)00082-2.

11. Floreani F, Martina L, Venuti S, Passon M. [Quick evaluation of work-related stress in the hospital environment] [Internet]. Firenze: PsyJob [cited 2016 Sep 21]. Available from: http://www.psyjob.it/valutazione-rapida-dello-stressazienda-ospedaliera.htm. Italian.

12. Ceschia A. [Impossible pace and risk of errors in heart surgery] [Internet]. Rome: Messaggero Veneto (Udine Edition) [cited 2016 Sep 21]. Available from: http://messaggeroveneto.gelocal.it/udine/cronaca/2013/08/29/news/a-cardiochirurgia-ritmi-impossibili-e-rischio-di-errori-1.7652948. Italian.

13. Linzer M, Manwell LB, Williams ES, Bobula JA, Brown RL, Varkey $\mathrm{AB}$, et al. Working conditions in primary care: Physician reactions and care quality. Ann Intern Med. 2009;151(1):28-36.

14. Goldman E, Plack M, Roche C, Smith J, Turley C. Learning in a chaotic environment. J Workplace Learn. 2009;21(7): 555-74, http://dx.doi.org/10.1108/13665620910985540.

15. Caruso CC. Negative impacts of shiftwork and long work hours. Rehabil Nurs. 2014;39(1):16-25, http://dx.doi.org/ 10.1002/rnj.107.

16. Valent F, Di Bartolomeo S, Marchetti R, Sbrojavacca R, Barbone F. A case-crossover study of sleep and work hours and the risk of road traffic accidents. Sleep. 2010;33(3):349-54.

This work is available in Open Access model and licensed under a Creative Commons Attribution-NonCommercial 3.0 Poland License - http://creativecommons.org/ licenses/by-nc/3.0/pl/deed.en. 